\title{
Clinical highlights from the 2011 ERS Congress in Amsterdam
}

\author{
Martijn A. Spruit*, Niels H. Chavannes\#, Felix J.F. Herth ${ }^{\star}$, Venerino Poletti ${ }^{+}$, \\ Sebastian Ley ${ }^{\S, f}$, Otto C. Burghuber**, Enrico Clini $^{\# \#}$ and Vincent Cottin ${ }^{\tau}{ }^{\star,++}$
}

\begin{abstract}
This article reports on selected papers pertinent to the most important clinical problems in the field of respiratory medicine. Expert authors from the Clinical Assembly of the European Respiratory Society (ERS) have selected updated reports related to presentations given at the 2011 ERS Annual Congress, which was held in Amsterdam (the Netherlands) and attended by more than 20,000 participants. The hot topics and selected abstracts from the scientific groups of the Clinical Assembly are discussed here in the context of recent literature.
\end{abstract}

KEYWORDS: Chronic obstructive pulmonary disease, cystic lung diseases, interstitial lung disease, interventional pulmonology, primary care, rehabilitation

$\mathbf{T}$ he 2011 European Respiratory Society (ERS) Annual Congress was successfully held in Amsterdam (the Netherlands) from September 24 to 28. As in recent years, the Congress was attended by more than 20,000 participants, making this Congress the largest meeting on a global scale in the field of respiratory medicine. More than 4,300 abstracts from research groups around the world were presented during the 4-day programme, including original data and outstanding lectures based on the most recent literature. This article reports results pertinent to the most important clinical problems in the field of respiratory medicine. The hot topics and the selected abstracts presented at the Congress from the six scientific groups (Clinical Problems, Interventional Pulmonology, Diffuse Parenchymal Lung Disease, Imaging, General Practice and Primary Care, and Rehabilitation and Chronic Care) of the Clinical Assembly are discussed here in the context of recent literature.

\section{CLINICAL PROBLEMS}

The main issues presented at the ERS Congress were updates on the diagnosis and management of chronic obstructive pulmonary disease (COPD), as well as updates exploring conditions other than COPD.

\section{Diagnosis of COPD and phenotyping}

At present, the diagnosis of COPD is typically considered to be a combination of clinical symptoms, exposure to risk factors and the presence of airflow limitation. The choice of measuring chronic airflow limitation has recently become a matter of debate [1]. Most authorities are in favour of a forced expiratory volume in $1 \mathrm{~s}$ (FEV1)/forced vital capacity (FVC) fixed ratio of $<0.7$, whereas some are in favour of using the lower limit of normal (LLN) cut-off points [2]. In an elegant presentation, VеSTBO [3] put this discussion into perspective by presenting unpublished data from the large Copenhagen City Heart Study that, on the one hand, proved the fact that fixed FEV1/FVC ratio creates false positives but, on the other hand, clearly pointed out that the difference between both methods appeared not to be clinically relevant. More importantly, COPD is not a disease characterised merely by airflow limitation. Indeed, we are still lacking a gold standard for the diagnosis of COPD and still rely on clinical symptoms, but we have to realise that it is a complex condition with extra-pulmonary effects. Indeed, several multi-component indices (BODE (Body mass index, the degree of airflow $\mathrm{Ob}$ struction, Dyspnoea, and Exercise capacity), DOSE (Dyspnoea, airflow Obstruction, Smoking status and Exacerbation frequency) and ADO (Age, Dyspnoea, airflow Obstruction)) have been proposed in recent years to better describe the disease and to establish the prognosis.

Considerable interest during the Congress was geared towards the issue of heterogeneity of COPD. The goal of phenotyping the disease is to identify patient groups with unique prognostic and therapeutic characteristics. A phenotype

\section{AFFILIATIONS}

*Program Development Centre of CIR0+, Centre of Expertise for Chronic Organ Failure, Horn, \#Dept of Public Health and Primary Care, Leiden University Medical Center, Leiden, The Netherlands "Dept of Pulmonary and Critical Care Medicine,

${ }^{\S}$ Dept of Diagnostic and Interventional Radiology, University of Heidelberg, Heidelberg, Germany. ${ }^{+}$Ospedale G.B. Morgagni-L.

Pierantoni, U.0. Pneumologia, Forli,

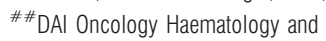
Respiratory Diseases - Ospedale Villa Pineta, University of ModenaReggio Emilia, Modena, Italy. fDept of Medical Imaging, University of Toronto, Toronto, ON, Canada. **Dept of Respiratory and Critical Care Medicine, Otto Wagner Hospital, Vienna, Austria. "Hospices Civils de Lyon, Hôpital Louis Pradel, Centre National de Référence des Maladies Pulmonaires Rares, and

+Université de Lyon, Université Lyon I Claude Bernard, INRA, UMR754 INRA-Vetagrosup EPHE IFR 128, Lyon, France.

\section{CORRESPONDENCE}

V. Cottin, Hospital Louis Pradel, Service de Pneumologie, 28 Avenue Doyen Lepine, 69677 Lyon, France. E-mail: vincent.cottin@chu-lyon.fr

Received:

Dec 122011

Accepted:

Dec 122011

First published online:

March 092012

This article was modified in

April 2016 to correct errors

in the licence information.

European Respiratory Journal Print ISSN 0903-1936

Online ISSN 1399-3003 
relates to "a single or combination of disease attributes that describe differences between individuals as they relate to clinically meaningful outcomes" [4]. Different clinical and physiological manifestations, the presence of systemic inflammation and comorbidities, acute exacerbations, and radiological characteristics are potential candidates for the identification of unique COPD phenotypes. Ongoing initiatives, such as the ECLIPSE (Evaluation of COPD to Identify Predictive Surrogate Endpoints), SPIROMICS (Subpopulations and intermediate outcome measures in COPD) and COPDGene studies, will shed new light on this topic in coming years. One possible phenotype recently established by the ECLIPSE investigators relates to that of the frequent exacerbations [5]; this seems important because acute exacerbations drive the progression of the disease, with increased morbidity and mortality as a result. In a recent observational study [6], it was shown that greater lung emphysema and airway wall thickness derived by quantitative computed tomography (CT), were associated with an independent increase in exacerbations, indicating a possible subgroup of COPD patients who experience frequent exacerbations that are unknown at present.

\section{Clinical audit in COPD}

Results from a European audit sponsored by the ERS, including 13 European countries and more than 400 hospitals, were presented in a symposium entitled "Optimising healthcare for COPD across Europe". Records from $>16,000$ COPD patients admitted to hospitals for acute exacerbations were collected to provide data on clinical performance that may be used to improve service delivery and, ultimately, patient care.

The admitted patients had severe COPD (mean FEV1 $41 \%$ of predicted value, $33 \%$ still smoking and $24 \%$ on long-term oxygen) but spirometry had been performed in only $60 \%$. More than $20 \%$ had cardiovascular (heart failure, hypertension or coronary artery disease) and metabolic (diabetes) comorbidities with significant negative impact on outcome. The overall length of hospital stay was 8 days, and in-hospital and 30-day mortality were $4.9 \%$ and $6.2 \%$, respectively. A higher inhospital mortality rate was recorded in those patients having pulmonary consolidations on chest radiographs $(8.1 \%)$ or hypercapnic acidosis $(14.5 \%)$ on admission. The readmission rate $(35 \%)$ varied between countries depending on facilities such as pulmonary rehabilitation at discharge [7].

\section{COPD treatment}

Interestingly, among the several updates during the Congress, several presentations dealt with innovative therapies. Experts highlighted that it takes longer for new respiratory drugs to come to the market as compared with cardiovascular medications and/or antibiotics. In this regard, patient phenotyping could be the way forward in providing more rapid access to new drugs. This was the case for roflumilast, a phosphodisterase-4 inhibitor, which opened a new phenotype-based therapeutic approach of COPD [8], now approved by both European and USA authorities. Indeed, robust and reproducible effects of this anti-inflammatory drug were only seen in patients at risk for frequent exacerbations and who had clinical symptoms of chronic bronchitis.

\section{Miscellanea}

Advances in the treatment of chronic cough have been reported in patients with eosinophilic bronchitis, showing a significant effect after inhalation of budesonide $200 \mu \mathrm{g}$ b.i.d. for 8 weeks [9], and in individuals with obstructive sleep apnoearelated cough, showing significant symptom reduction by using continuous positive airway pressure for 1 month [10].

Updates were also reported in the diagnosis and management of pneumonia. The level of inflammatory biomarkers (interleukin (IL)-2 and IL-6, tumour necrosis factor- $\alpha$ ) on the day of admission are able to predict the risk of a poor outcome in community-acquired pneumonia (CAP) [11], whereas the degree of pulmonary hypertension is likely to predict recurrent CAP in young patients (aged $<18$ yrs) with connective tissue diseases [12]. A specific composite score (clinical pulmonary infection score; CPIS) may help with the treatment decision in patients with hospital-acquired pneumonia during their stay in hospital [13]. An addition to the expanding list of new professions (workers in a salami factory) involved in the acute onset of hypersensitivity pneumonitis (due to Penicillium antigens) was also reported [14]. Finally, one study tackled the clinical problems related to end-stage respiratory failure following interstitial lung diseases. In a retrospective study, the need for palliative therapies was assessed, which, interestingly, showed that opioids and benzodiazepines were used with a documented benefit in almost $50 \%$ of patients [15].

\section{INTERVENTIONAL PULMONOLOGY}

New experiences with endoscopic interventions for patients with severe lung disease, the use of endobronchial ultrasound as a leading technology for diagnosis and mediastinal staging of lung cancer were the main topics discussed at the Congress.

\section{Endoscopic lung volume reduction}

Accurate patient selection is the most important and difficult issue for endoscopic lung volume reduction (ELVR). Therefore, treatment algorithms are needed to identify those who will benefit the most. Principally, patients with severe emphysema should be screened by full lung function testing, including diffusing capacity of the lung for carbon monoxide, blood gas analysis and field exercise test (6-min walk test (6MWT)). Distribution of emphysema and fissure integrity need to be assessed by high-resolution CT (HRCT) at full inspiration and by perfusion scan to evaluate the degree of collateral ventilation [16]. Patients with quite well-recognised functional characteristics (FEV1 $<45 \%$, total lung capacity $>100 \%$, residual volume $>150 \%$ of pred, arterial carbon dioxide tension $\leqslant 60 \mathrm{mmHg}$, arterial oxygen tension $\leqslant 45 \mathrm{mmHg}$ and $>140 \mathrm{~m}$ in the 6MWT) are likely to benefit from ELVR.

Complete lobar occlusion by valve implantation provides an effective option for patients with heterogeneous upper or lower lobe predominant emphysema and low collateral ventilation. However, irreversible and non-blocking endoscopic techniques are more effective in patients with upper lobe predominant emphysema and high collateral ventilation.

Valves

Two different valves are commercially available, endobronchial (Zephyr®; Pulmonx Inc., Palo Alto, CA, USA) and intrabronchial (Spiration ${ }^{\circledR}$; Olympus Inc., Tokyo, Japan), with 
two different implantation modes, i.e. unilateral lobar occlusion or bilateral partial closure, which lead to redistribution of ventilation, but avoid atelectasis. A randomised study comparing these modes in 20 patients with severe upper lobe predominant emphysema has shown a greater benefit in terms of both FEV1 and 6MWT in patients receiving the unilateral ELVR with complete lobar occlusion, despite a higher risk of pneumothorax [17].

\section{Lung volume reduction coils}

This consists of implantation of nitinol wire(s) in the airway (PneumRx Inc., Mountain View, CA, USA) under bronchoscopy, resulting in parenchymal compression and achievement of volume reduction (fig. 1). Only one open study with lung volume reduction coils (10 coils per lobe, placed bilaterally in 12 out of 16 cases) demonstrated significant improvements in pulmonary function, exercise capacity and quality of life, with an acceptable safety procedure [18].

Polymeric lung volume reduction

This technique involves administering a foam sealant (Aeris Therapeutics Inc., Woburn, MS, USA) into the compromised lung compartments, leading to a local inflammatory reaction and scar formation (fig. 2), with subsequent volume reduction. Polymeric lung volume reduction can be offered to patients with heterogeneous, as well as with homogeneous, disease. In a multicentre study in 25 patients with upper lobe predominant emphysema, polymeric lung volume reduction produced the greatest physiological and clinical effects in Global Initiative for Chronic Obstructive Lung Disease (GOLD) stage IV of COPD [19].

\section{Bronchoscopic thermal vapour ablation}

This is an alternative method to polymeric lung volume reduction and consists of delivering heated water vapour through a vapour generator and a special bronchoscopic catheter (Uptake Medical, Seattle, WA, USA) to the most destroyed lung regions, thus inducing a local inflammatory reaction (fig. 3). A multinational study evaluated the efficacy of bronchoscopic thermal vapour ablation (vapour dose $\left.42 \mathrm{~J} \cdot \mathrm{g}^{-1}\left(10 \mathrm{cal} \cdot \mathrm{g}^{-1}\right)\right)$ in 44 patients with upper lobe predominant emphysema. Volume reduction $(48 \%)$ of the treated lobe, as assessed by HRCT, was reported after 6 months:
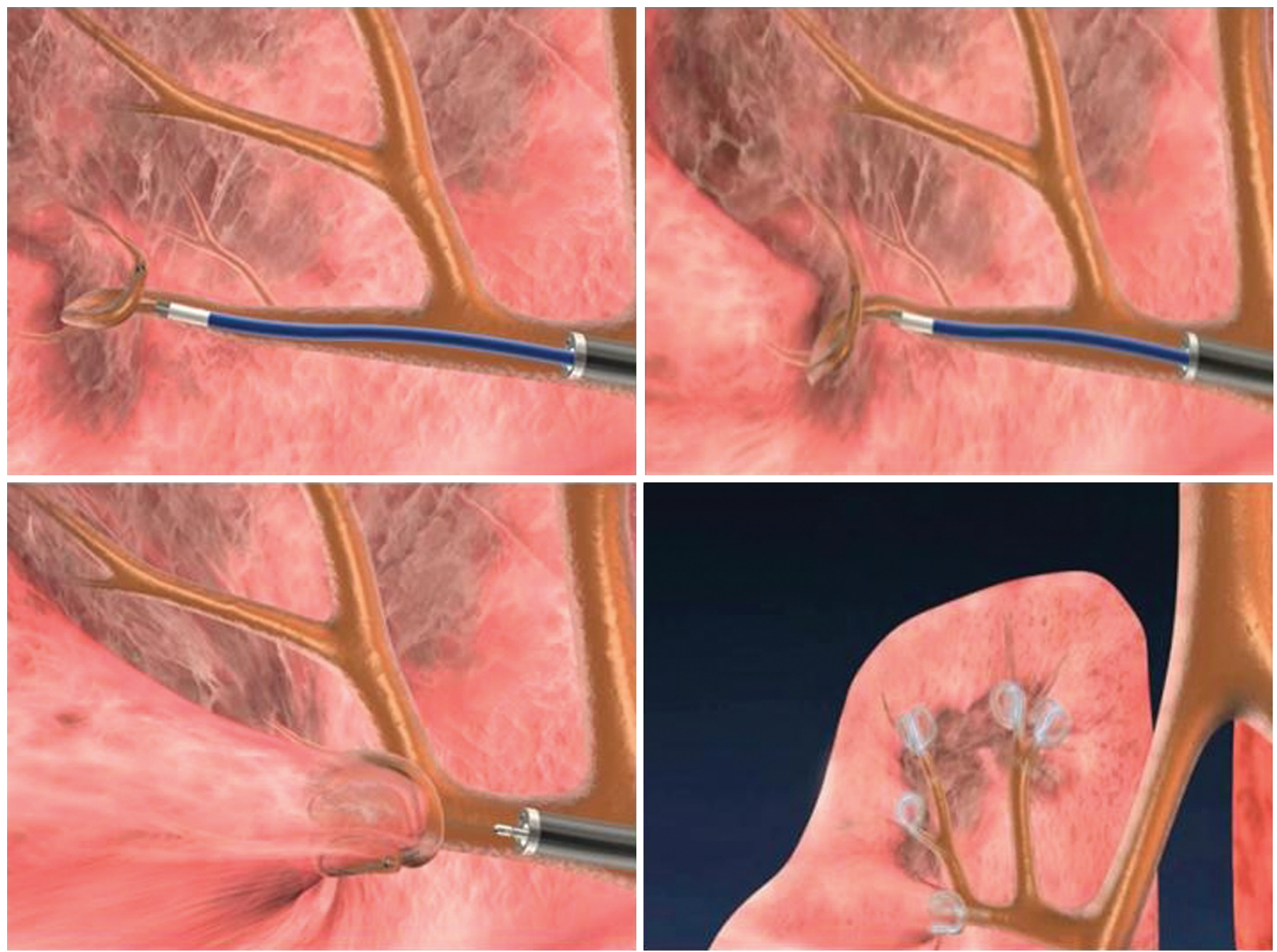

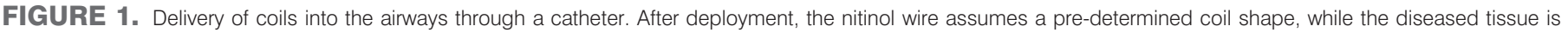
compressed. 

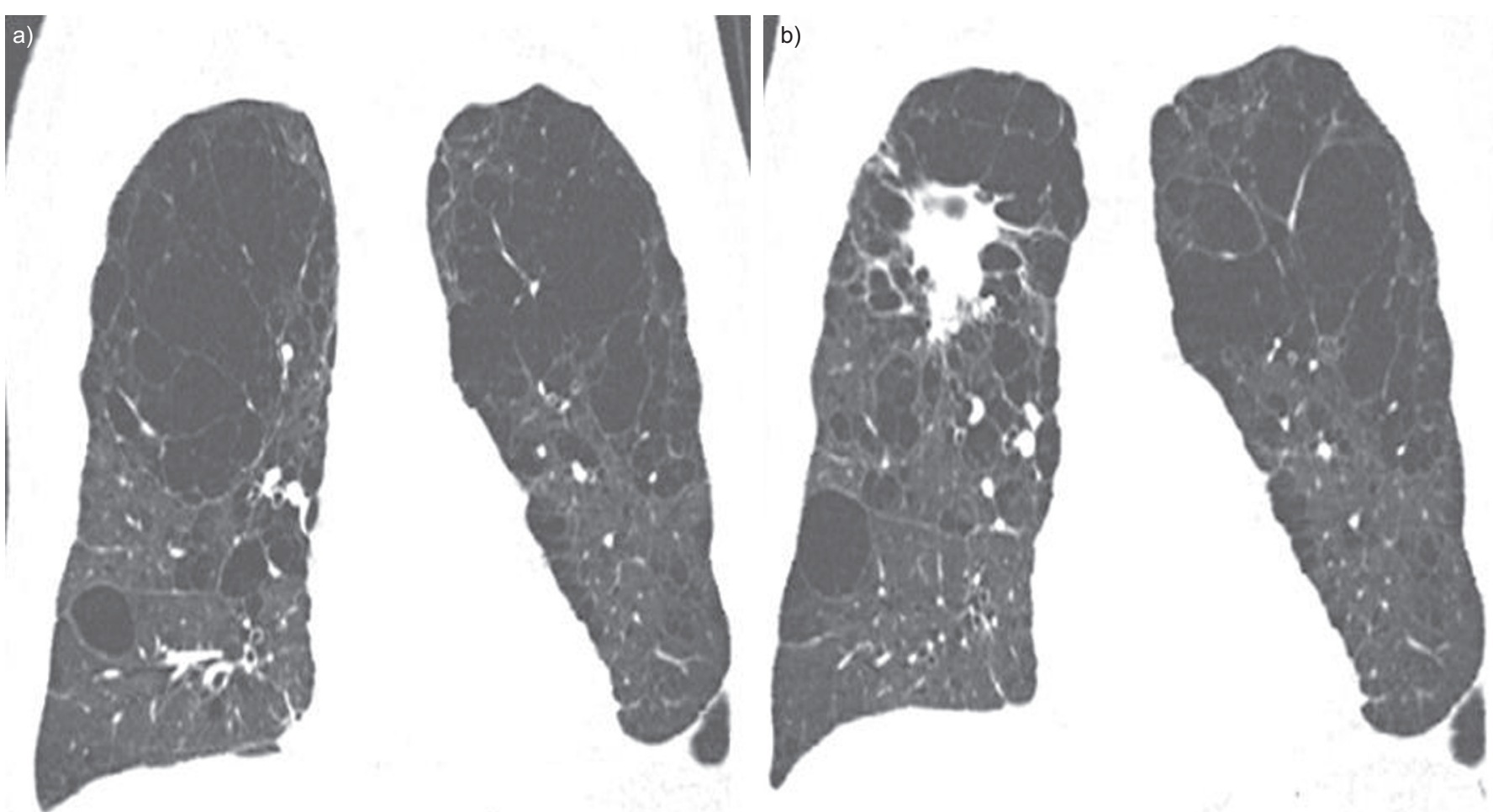

FIGURE 2. Effect of the application of polymeric lung volume reduction for endodcopic lung volume reduction. Scar tissue is visible on coronal computed tomography images in the right upper lobe after intervention (b) 6-8 weeks after treatment.

exacerbations, pneumonia and haemoptysis were anecdotally reported after the treatment [20].

\section{Endobronchial ultrasound}

Mediastinal nodal sampling has traditionally been performed using surgical techniques that may result in significant morbidity and mortality. Endoscopic ultrasound (EBUS) to guide transbronchial needle aspiration (TBNA) of mediastinal lymph nodes has been developed as a safer, less invasive and more cost-effective procedure [21, 22].

Potentially, this technique may yield cytological specimens inadequate of providing a firm diagnosis. Indeed, immunohistochemistry and mutational analysis from sufficiently large tissue samples are extremely important in the process of
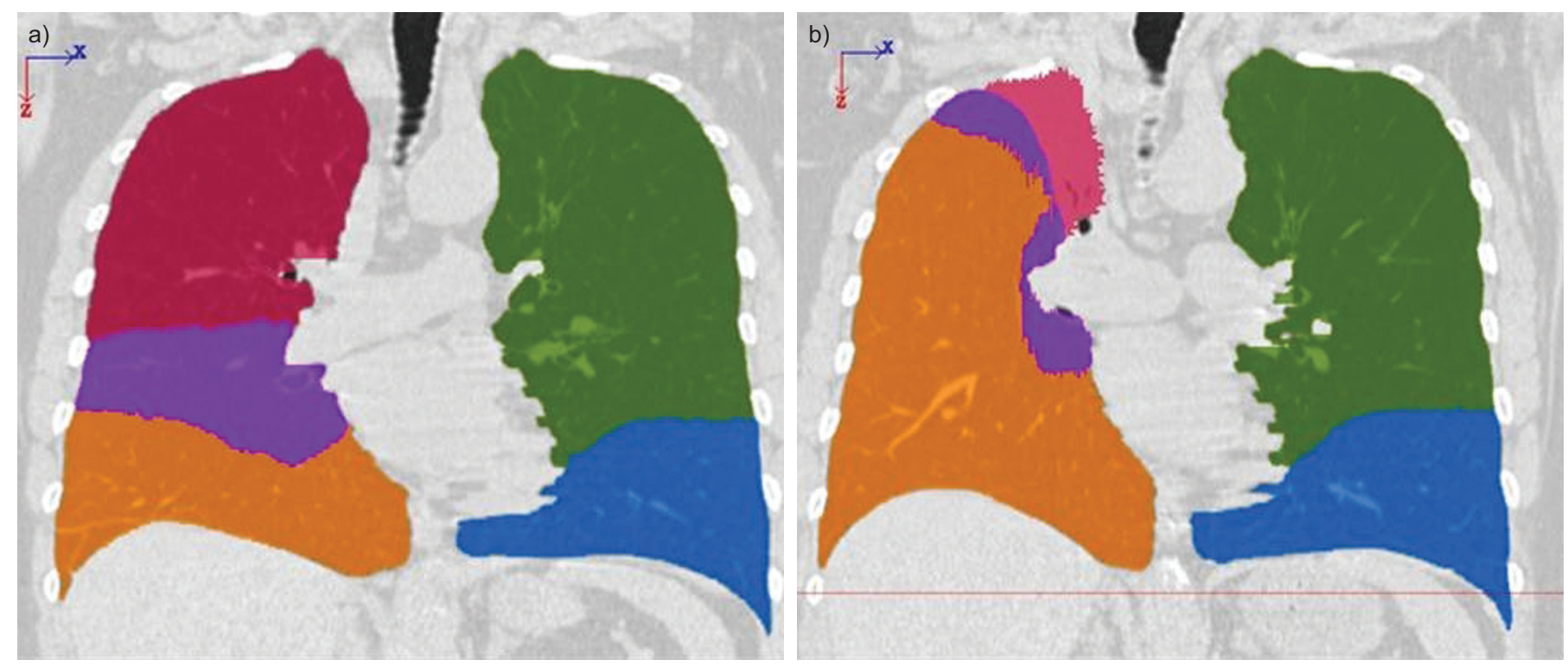

FIGURE 3. a) Pre- and b) post-changes (3 months) after bronchoscopic thermal vapour ablation of the right upper lobe. Tissue volume changes can be seen on coronal computed tomography images in the panels. Each lobe is represented by coloured overlays. 
establishing a diagnosis of lung cancer; a substantial proportion of tumours express mutations of cell surface receptors (i.e. epidermal growth factor receptor) at which specific molecules, such as gefitinib and erlotinib, may direct their anti-proliferative effect. In past years, tests for mutations could only be performed on block tumours post-resection. However, more recent advances in molecular biology led to the ability to also test small biopsy specimens for such mutations by PCR analysis, fluorescence in situ hybridisation and immunohistochemistry. As shown during the ERS Congress, EBUS-TBNA offers the opportunity to obtain adequate samples through a nonsurgical biopsy technique, allowing combined pathological and molecular analysis of metastatic lymph nodes to be performed [23-26].

\section{DIFFUSE PARENCHYMAL LUNG DISEASES}

Clinical characterisation and new frontiers in the therapy of idiopathic pulmonary fibrosis (IPF), as well as rare diseases of the lung appearing with cystic lesions were significant topics reported during the ERS Congress.

\section{Advances in the definition of IPF}

Different patterns of interstitial lung disease frequently (up to $4 \%$ ) occur among smokers screened for lung cancer [27], showing that both conditions may share some pathogenetic mechanisms [28]. IPF is the most common of the idiopathic interstitial pneumonias and is associated with tobacco smoking.

A recent consensus providing simplified criteria for the diagnosis of IPF emphasised the importance of multidisciplinary discussion between clinicians, radiologists and pathologists in improving diagnostic confidence [29]. The pattern of usual interstitial pneumonia (UIP) (subpleural reticular abnormality and honeycombing, with or without traction bronchiectasis, in the lung basal regions) on chest HRCT in the absence of other known causes for UIP is typical, thus emphasising the diagnostic role of imaging. However, extensive ground-glass opacity, profuse micronodules, cysts, diffuse air-trapping or alveolar consolidation in the upper/mid lobes are more likely to be "inconsistent with UIP". The histopathological lesions that characterise the UIP pattern are patchy areas of fibrosis (excessive collagen deposition), honeycomb changes, the mandatory presence of fibroblastic foci and, at the same time, the absence of any feature suggesting an alternative diagnosis [30]. Thus, combinations of HRCT and results of the lung biopsy, when available, may result in four categories of diagnostic certainty in IPF (IPF, probable IPF, possible IPF and not IPF).

Nonetheless, the clinical profile and patterns defined by imaging and pathology are not yet completely defined. First, the inter-observer agreement to recognise honeycombing change decreases when pulmonary fibrosis and emphysema coexist [30]. Secondly, immunohistochemistry other than the usual haematoxylin-eosin stain could be more useful for an objective morphological definition [31]. Thirdly, IPF shows clinical and radiological heterogeneity, such as that documented in the asymmetrical disease, associated with a higher rate of gastro-oesophageal reflux and of episodes of acute exacerbations [32]. Fourthly, serum biomarkers could help both diagnosis and prognosis in the near future [33]. Finally, easily available clinical data, such as age $>65$ yrs, modest amounts of fibrosis on HRCT scan [34] and family history of pulmonary fibrosis [35], may also help to suspect a diagnosis of IPF, which is not the case for other parameters (sex, smoking habit, lung function, oxygen abnormalities and distance walked in the 6MWT). As a matter of fact, a "benign" clinical course is reported in patients with a diagnosis of idiopathic nonspecific interstitial pneumonia [36].

\section{Therapeutic options in IPF}

Studies evaluating the efficacy of nonsteroid agents in large cohorts of patients with mild or moderate IPF have created new expectations for the therapy of this disease [37], and good news is expected from ongoing placebo-controlled trials using new and more specific molecules.

Recent clinical trials supported the role of pirfenidone to limit the decline of lung function and to improve time to disease progression in these patients, with an acceptable tolerability and safety profile [38]. More recently, the efficacy and safety of a potent intracellular inhibitor of tyrosine kinases (BIBF 1120) was assessed in a 12-month, phase-II trial, also including patients with mild-to-moderate IPF. At a dose of $150 \mathrm{mg}$ b.i.d., the drug showed a positive trend toward a reduction in the decline of lung volumes, with fewer acute exacerbations and preserved quality of life [39].

\section{Cystic lung diseases}

The spectrum of diseases appearing with cystic changes in the lungs is widening [40], and may mimic those of lymphangioleiomyomatosis. Among these, severe bronchiolitis has been reported as a presenting feature of the primary Sjögren's syndrome [41], while genetic mutations [42, 43] and other congenital disorders [44] have been recognised as a cause of cysts in the lung with familial spontaneous pneumothorax, and rare lung or extra-pulmonary tumours.

Finally, chronic damage to the small airways (such as during exposure to inhalants or in the case of neuro-endocrine bronchiolar hyperplasia) [45], and non-amyloid immunoglobulin deposition disease may rarely determine cystic lung lesions.

\section{CHEST IMAGING}

To date, imaging is used for the morphological assessment of lung parenchymal diseases. Although pulmonary function evaluation is considered more important for staging and follow-up than imaging in most lung diseases, emerging imaging technologies and strategies might get this target more and more into reach.

\section{Functional imaging}

$\mathrm{CT}$ is the most established technique for visualisation of the lung parenchyma. Image acquisition can be triggered to respiration (four-dimensional (4D)-CT) so that the ventilated lung volumes during free breathing can be assessed [46]; furthermore, the regional motion of the lung parenchyma can be traced, thus, generating motion maps. A high agreement $(r=0.93)$ for ventilation defects was found in comparison with ventilation single photon emission CT imaging [47]. As a drawback of the $4 \mathrm{D}-\mathrm{CT}$ technique, a high radiation dose has to be administered, and perfusion cannot be assessed at the same time. 
To overcome these restrictions, magnetic resonance imaging (MRI) techniques have been deployed. A novel method for generating ventilation/perfusion $\left(V^{\prime} / Q^{\prime}\right)$ maps was presented at the 2011 ERS Congress. This was based on oxygen-enhanced MRI performing a model fitting calculation of the pulmonary perfusion [48]. In contrast with healthy volunteers, $V^{\prime} / Q^{\prime}$ was found to be increasingly heterogeneous in patients with moderate-to-severe COPD, with no difference between the subgroups with or without emphysema [49]. Therefore, these techniques allow for assessment of the functional impact of typical morphological changes with a high-spatial resolution.

Another important aspect of lung pathophysiology is the regional compliance of the lung parenchyma [50]. Noninvasive assessment of this parameter is difficult but could be important for validation of new treatment options in diseases such as pulmonary fibrosis or COPD. A recently proposed MRI method facilitating dynamic imaging of the lung parenchyma has shown a significant increase of lung compliance in COPD patients compared with healthy volunteers [51].

\section{Image-based characterisation of COPD}

Since CT is the standard for imaging the lung parenchyma, it may be used in longitudinal studies to assess changes in parenchymal density and lung mass or treatment response.

Based on data from the Danish Lung Cancer Screening Trial, 2,052 people were examined over 5 yrs with annual CT scans [52]. The annual decline in volume density of male ex-smokers (reference group) was $-0.38 \mathrm{~g} \cdot \mathrm{L}^{-1} \cdot \mathrm{yr}^{-1}$, with $\sim 70 \%$ increased rates of decline in females, current smokers and in subjects with airflow obstruction. Data suggest these characteristics are factors influencing the change in lung density that needs to be taken into account for evaluation in prospective studies.

Phenotyping of emphysematous lung changes is also a new approach to characterise patient groups and to predict their outcome. The lobar predominance of emphysema was assessed at baseline and after 2.9 yrs in a cohort of 587 patients [53]; participants with upper lobe emphysema had an additional risk $(+71 \%)$ of decreased FEV1/FVC at follow-up when compared to patients with lower lobe emphysema $(p=0.001)$, independent of the total extent of the disease. Therefore, it might be argued that upper lobe predominant disease is a specific phenotype of emphysema.

With specific regard to COPD, some patients show more enhanced changes in the lung parenchyma while others do show more airway disease. The tracheo-bronchial collapsibility has been assessed using inspiratory-expiratory CT in relationship to the specific phenotype in 36 patients [54]; this index was significantly higher in patients with chronic bronchitis $(p=0.02)$, suggesting that a similar inflammatory process could involve both trachea and the bronchial tree.

\section{GENERAL PRACTICE AND PRIMARY CARE}

In the field of general practice, several sessions at the ERS Congress and during the Primary Care Day reported on recent developments aimed at establishing an early, but valid, diagnosis; thus, improving the quality of patient care and disease management, and keeping on track with promising advances in tele-health and integrated care.

\section{Early diagnosis and quality of assessment}

In a pilot study, HAROON et al. [55] investigated the yield of a targeted approach (questionnaire) for case finding versus an opportunistic approach (visit to a general practitioner (GP)). Patients with symptoms were invited to attend spirometry and those showing airway obstruction were referred to the primary care level. Only $1.2 \%$ in the targeted arm and $1.5 \%$ in the opportunistic arm were identified with airway obstruction.

In a Danish study [56], the authors assessed the effectiveness of a two-stage screening programme by posting a questionnaire to subjects aged $\geqslant 65$ yrs, followed by spirometry in (former) smokers or when experiencing morning cough with sputum and/or dyspnoea. A total of 1,352 (19\%) subjects performed spirometry. Of these, $44 \%$ were diagnosed to have mild (42\%), moderate $(43 \%)$ or severe-to-very severe (14\%) COPD.

Non-routine healthcare utilisation in the $2-10$ yrs prior to COPD diagnosis was analysed by PRICE et al. [57] in a large retrospective observational study. In the $2 \mathrm{yrs}$ prior to diagnosis, $56 \%$ of patients were consulted for respiratory complaints ( $26 \%$ for lower respiratory tract infections) and most of them $(34 \%)$ received multiple prescriptions for oral steroids and/or antibiotics. The same patients recorded more hospitalisations over the 4 yrs prior to diagnosis.

To assess adherence to GOLD guidelines and appropriateness of prescribing, ВоOTH et al. [58] extracted data on COPD management in 65 general practices. Spirometry was recorded for $2,941(61 \%)$ individuals, with confirmed diagnosis of COPD in 2,163 . Up to $62 \%$ were inappropriately treated according to GOLD, with over-prescription of inhaled corticosteroids in GOLD stage I/II (55\%), or in stage III/IV with no history of severe exacerbations (56\%) being the most common deviation.

The quality of health services was recorded at primary care level in 200 Indian patients with asthma [59]. Around 15\% of the subjects were being treated by unqualified practitioners and $<50 \%$ by GPs. Among those treated by unqualified practitioners, $64 \%$ were being inappropriately prescribed bronchodilators and oral corticosteroids. In the same field of asthma management, TERMEER et al. [60] explored the consequences of using exhaled nitric oxide fraction ( $F \mathrm{eNO}$ ) as an adjunct to symptoms and spirometry for assessing disease control in Dutch primary care. In almost half the population, FeNO may result in fine-tuning of the categorisation of asthma control.

Finally, MENZIES and Wiggins [61] investigated the use of pulse oximeters by GPs in the UK, and found that over a third of them did not yet own the device, despite current guideline indications for assessment and management and the fact that most of the users $(89 \%)$ did consider this tool very useful.

\section{Managing comorbidities}

The associations between comorbidity and mortality were investigated in 552 Swedish COPD patients [62]. Over a 5-yr period, $22 \%$ of the patients died; adjusted mortality rates were significantly higher in patients with cardiac diseases and hypertension and who were underweight. Interestingly, GIL et al. [63] investigated the risk of treating patients with both heart failure and mild-to-moderate COPD with $\beta$ blockers. In all 43 patients with an average ejection fraction 
of $29 \%$, tailored treatment revealed no acute episodes of respiratory failure over the following year. The specific problem of coexisting left heart failure in COPD has been evaluated in 101 patients in a cohort of $\sim 800$ subjects in the UK [64]. Although the coexistence of heart failure and COPD was associated with increased hospitalisations, 2-yr survival was similar in these patients $(89 \%)$ when compared with heart failure alone (93\%).

\section{Telemedicine and integrated care}

In recent years, the interest in telemonitoring services for COPD patients has grown considerably. Patients may use teledata to determine their state of health and to validate their decision to contact healthcare professionals earlier in order to prevent admissions. Conversely, professionals may emphasise the role of telemetry in encouraging compliance and facilitating patient self-management. FAIRBROTHER et al. [65] explored the views of patients and professionals participating in a trial on home telemonitoring, and showed that both sides perceived that this service reduced the risk of re-admission.

BOONSAWAT [66] reported a large-scale (900 hospitals serving 99,535 asthmatics) implementation of asthma guidelines through the Easy Asthma Clinic in Thailand. Peak flow measurement performance improved from 1\% to $98 \%$, inhaled corticosteroid use increased from $11 \%$ to $79 \%$ throughout the visits, and asthma control was fully (23\%) or partially $(46 \%)$ achieved. In another implementation study in the Netherlands, the authors hypothesised that a secured web-based telespirometry service would reduce referrals and improve triage among respiratory patients [67]. $75 \%$ of the teleconsultations originally intended for referral were prevented, whereas $22 \%$ of the teleconsultations for advice were referred for further investigation.

In the same country, PRINSEN et al. [68] described the effect of clinical advice (from pulmonologist to GP) from an integrated care system on health status in COPD patients. Over time, improvement or deterioration of health status was measured in $27 \%$ and $29 \%$ of patients, respectively. Although this care model demonstrated statistically significant benefit to COPD health status, the clinical implications remain unclear.

\section{REHABILITATION AND CHRONIC CARE}

Multiple abstracts were presented at the 2011 ERS Congress covering the area of rehabilitation and chronic care. Five young scientists were awarded a sponsored grant for Best Abstracts in Rehabilitation and Chronic Care.

\section{Impact of comorbidities}

Systemic inflammation may initiate or worsen comorbid diseases (ischaemic heart disease, heart failure, osteoporosis, depression and diabetes) in patients with COPD; the spill-over of inflammatory mediators into the circulation of these patients has been suggested as a possible mechanism [69]. Recently, multiple markers of systemic inflammation have been associated with an increased fat mass in these patients [70, 71]. VAN DEN BORST et al. [72] hypothesised that visceral adipose tissue is related to systemic inflammation in subjects with clinically stable obstructive lung disease (defined as FEV1/FVC below LLN). Obstructive lung disease subjects had greater visceral adiposity and elevated levels of IL-6, plasminogen activator inhibitor-1 and adiponectin compared with matched controls, while whole-body and appendicular/trunk fat mass were comparable. Therefore, higher visceral adipose tissue may reflect a disturbed metabolic function contributing to systemic manifestations. Whether variation in visceral adipose tissue distribution contributes to the prevalence of obesity-related diseases and whether comprehensive rehabilitation, including aerobic exercise training and nutritional counselling, may benefit patients with airway obstruction still remains unknown. Nevertheless, aerobic exercise is central for exercise programmes aimed at reducing visceral adipose tissue, and aerobic exercise below current recommendations for obesity management may be sufficient for beneficial visceral adipose tissue modification [73].

\section{Exercise modalities and physiological response}

Exercise training is recognised as the cornerstone of comprehensive pulmonary rehabilitation programmes in patients with chronic respiratory disease [74]. High-intensity interval training can be considered as an alternative to continuous training in patients with varying degrees of COPD severity to improve exercise performance and health status $[75,76]$. GLOECKL et al. [77] compared the feasibility and effects of high-intensity interval (30-s exercise bouts at $100 \%$ of baseline peak load and 30 -s rest for $10-30 \mathrm{~min}$ ) with continuous $(60 \%$ of baseline load for $12-36 \mathrm{~min}$ ) volume-equivalent training in 60 in-patients with COPD before lung transplantation during a 3-week programme. While exercise performance improved significantly to the same extent in both groups, as demonstrated in previous studies in the moderate stage of the disease [78], dyspnoea scores and the number of unintended stops were higher during the continuous modality, showing that highintensity interval training seems better tolerated by the most severe patients.

Local lower-limb muscle training, like high-intensity resistance training or transcutaneous neuromuscular electrical stimulation, has also been shown to be beneficial $[79,80]$. In a randomised, double-blind, placebo-controlled trial, HoUCHEN et al. [81] studied the enhancing effects of protein supplementation during an 8-week resistance training programme (five times 30 bilateral knee extensions three times a week) in 59 patients with moderate-to-severe COPD; lower-limb muscle function, thigh lean mass and peak exercise performance improved compared with baseline similarly in patients with or without supplementation. This further confirms that resistance training is feasible and effective in COPD patients [82] but the addition of a protein supplement did not augment the functional benefits.

Whole-body exercise testing and high-intensity exercise training may result in dynamic hyperinflation and large intrathoracic pressure swings [83], which may further compromise the impaired cardiac output in the COPD population [84]. VASILOPOULU et al. [85] studied the effect of disease severity on haemodynamic responses during a $6 \mathrm{MWT}$ and cycling at a constant $75 \%$ of the peak power output in 60 COPD patients in GOLD stages I to IV. Cardiac output kinetics were similar between both exercise tests, but a GOLD stage-dependent increase was observed for on-transient and off-transient time constants (i.e. slowest) in GOLD stage IV patients, reflecting a 
greater cardiovascular impairment in patients with more advanced disease and/or deconditioning.

\section{End-of-life in chronic diseases}

JANSSEN et al. [86] investigated 1-yr stability of preferences regarding cardiopulmonary resuscitation and mechanical ventilation in 265 patients with advanced COPD, or chronic heart or renal failure, and identified that preferences changed at least once in $38 \%$ of the patients during the follow-up. A change from preferring life-sustaining treatment to refusing such treatment was predicted by a decrease in health status and mobility, and by an increase in symptoms of anxiety and depression; a change from refusing to preferring life-sustaining treatment was also predicted by a decrease in health status, as well as by the loss of a spouse [87]. These data suggest that regular re-evaluation of advance care planning is necessary in patients with chronic disease.

\section{STATEMENT OF INTEREST}

Statements of interest for E. Clini and V. Cottin can be found at www. erj.ersjournals.com/misc/site/statements.xhtml

\section{REFERENCES}

1 Fabbri LM. FEV1/FVC fixed ratio again. Chest 2011; 139: 12521253.

2 Celli BR, Halbert RJ. Point: should we abandon FEV1/FVC $<0.70$ to detect airway obstruction? No. Chest 2010; 138: 1037-1040.

3 Vestbo J. Making sense of COPD definitions and data to the general practitioner, the pulmonologist and the epidemiologist. European Respiratory Society Annual Congress (September 2011, Amsterdam). Available from: www.ers-education.org/pages/ default.aspx? $\mathrm{id}=2684 \&$ idBrowse $=106222$

4 Han MK, Agusti A, Calverley PM, et al. Chronic obstructive pulmonary disease phenotypes: the future of COPD. Am J Respir Crit Care Med 2010; 182: 598-604.

5 Hurst JR, Vestbo J, Anzueto A, et al. Susceptibility to exacerbation in chronic obstructive pulmonary disease. N Engl J Med 2010; 363: 1128-1138.

6 Han MK, Kazerooni EA, Lynch DA, et al. Chronic obstructive pulmonary disease exacerbations in the COPDGene study: associated radiologic phenotypes. Radiology 2011; 261: 274-282.

7 Hartl S, Lopez-Campos J, Roberts M, et al. Provision of nonpharmacological treatment options for COPD patients in 13 European countries: results from the European COPD audit. Eur Respir J 2011; 38: Suppl. 55, 887s.

8 Fabbri LM, Beghé B, Yasothan U, et al. Roflumilast. Nat Rev Drug Discov 2010; 9: 761-762.

$9 \mathrm{Xu} \mathrm{D}, \mathrm{Lai} \mathrm{K}, \mathrm{Xie} \mathrm{J}$, et al. Different treatment courses of inhaled corticosteroids for eosinophilic bronchitis. Eur Respir J 2011; 38: Suppl. 55, 65s.

10 Chan K, Cossa G, Laks L, et al. Impact on objective cough severity by continuous positive airway pressure in subjects with chronic cough and obstructive sleep apnoea - a randomized controlled trial. Eur Respir J 2011; 38: Suppl. 55, 65s.

11 Kolosov VP, Kochegarova EV, Naryshkina EY. Prediction of complications development and lethal outcome in patients with community acquired pneumonia. Eur Respir J 2011; 38: Suppl. 55, $67 \mathrm{~s}$.

12 Nesterenko Z, Ivanina O. Community-acquired pneumonia in pediatric patients with connective tissue disorders. Manifestations and clinical course. Eur Respir J 2011; 38: Suppl. 55, 542s.

13 Basarik B, Ozdemir P, Tusakaban SM, et al. Contribution of clinical pulmonary infection score in the diagnosis of hospital acquired pneumonia. Eur Respir J 2011; 38: Suppl. 55, 67s.
14 Balzarini L, Mancini C, Mouzakiti P, et al. Clinical features of a new hypersensitivity pneumonitis: salami brusher's disease. Eur Respir J 2011; 38: Suppl. 55, 543s.

15 Bajwah S, Higginson IJ, Ross J, et al. Specialist palliative care is more than drugs - a retrospective study of ILD patients. Eur Respir J 2011; 38: Suppl. 55, 542s.

16 Sciurba FC, Ernst A, Herth FJF, et al. A randomized study of endobronchial valves for advanced emphysema. $N$ Engl J Med 2010; 363: 1233-1244.

17 Eberhardt R, Gompelmann D, Schuhmann M, et al. Unilateral vs. bilateral endoscopic lung volume reduction in patients with severe heterogeneous emphysema: a comparative randomised case study. Eur Respir J 2010; 36: Suppl. 54, 612s.

18 Slebos DJ, Klooster K, Hetzel M, et al. Lung volume reduction coil treatment for patients with severe heterogeneous emphysema, a multicenter feasibility trial. Eur Respir J 2011; 38: Suppl. 55, 371s.

19 Kramer M, Fruchter O, Maimon MN, et al. Single session bilateral endoscopic lung volume reduction therapy in advanced upper lobe and homogeneous emphysema using a tissue sealant. Eur Respir J 2011; 38: Suppl. 55, 369s.

20 Herth F, Snell G, Hopkins P, et al. Sustained efficacy from 3 to 6 months following bronchoscopic thermal vapor ablation (BTVA) in the treatment of heterogeneous emphysema. Eur Respir J 2011; 38: Suppl. 55, 370s.

21 Adams K, Shah PL, Edmonds L, et al. Test performance of endobronchial ultrasound and transbronchial needle aspiration biopsy for mediastinal staging in patients with lung cancer: systematic review and meta-analysis. Thorax 2009; 64: 757-762.

22 Herth FJ, Krasnik M, Kahn N, et al. Combined endoscopicendobronchial ultrasound-guided fine-needle aspiration of mediastinal lymph nodes through a single bronchoscope in 150 patients with suspected lung cancer. Chest 2010; 138: 790-794.

23 Van Breda A, von Bartheld B, Annema JT. Complication rate of EUS-FNA and EBUS-TBNA in mediastinal nodal aspiration: a meta-analysis. Eur Respir J 2011; 38: Suppl. 55, 15s.

24 Szlubowski A, Kocon P, Soja J, et al. A comparison of the combined ultrasound of the mediastinum by use of a single EBUS scope versus two scopes EBUS and EUS for lung cancer staging - A prospective study. Eur Respir J 2011; 38: Suppl. 55, 15s.

25 Krasnik M, Mellemgaard A, Jakobsen E. Does routine use of EBUS-TBNA and EUS-FNA improve the accuracy of staging of non small cell lung cancer patients - a national tumor registry based study. Eur Respir J 2011; 38: Suppl. 55, 342s.

26 Andrade MI, Gutierrez T, Iridoy A, et al. Time to diagnostic procedures and treatment in outpatients diagnosed of lung cancer (LC) included in our rapid diagnose protocol (RPD). Eur Respir J 2011; 38: Suppl. 55, 849s.

27 Sverzellati N, Guerci L, Randi G, et al. Interstitial lung diseases in a lung cancer screening trial. Eur Respir J 2011; 38: 392-400.

28 Vancheri C, Failla M, Crimi N, et al. Idiopathic pulmonary fibrosis: a disease with similarities and links to lung cancer. Eur Respir J 2010; 35: 496-504.

29 Raghu R, Collard HR, Egan JJ, et al. An official ATS/ERS/JRS/ ALAT statement: idiopathic pulmonary fibrosis: evidence-based guidelines for diagnosis and management. Am J Respir Crit Care Med 2011; 183: 788-824.

30 Akira M, Inoue $\mathrm{Y}$, Kitaichi M, et al. Usual interstitial pneumonia and nonspecific interstitial pneumonia with and without concurrent emphysema. Radiology 2009; 251: 271-279.

31 Chilosi M, Doglioni C, Murer B, et al. Epithelial stem cell exhaustion in the pathogenesis of idiopathic pulmonary fibrosis. Sarcoidosis Vasc Diffuse Lung Dis 2010; 27: 7-18.

32 Tcherakian C, Cottin V, Brillet PY, et al. Progression of idiopathic pulmonary fibrosis: lessons from asymmetrical disease. Thorax 2011; 66: 226-231. 
33 Richards TJ, Kaminski N, Baribaud F, et al. Peripheral blood proteins predict mortality in idiopathic pulmonary fibrosis. Am J Respir Crit Care Med 2012; 185: 67-76.

34 Fell CD, Martinez FJ, Liu LX, et al. Clinical predictors of a diagnosis of idiopathic pulmonary fibrosis. Am J Respir Crit Care Med 2010; 181: 832-837.

35 Garcia-Sancho C, Buendia-Roldan I, Fernandez-Plata MR, et al. Familial pulmonary fibrosis is the strongest risk factor for idiopathic pulmonary fibrosis. Respir Med 2011; 105: 1902-1907.

36 Romagnoli M, Nannini C, Piciucchi S, et al. Idiopathic nonspecific interstitial pneumonia: an interstitial lung disease associated with autoimmune disorders? Eur Respir J 2011; 38: 384-391.

37 Spagnolo P, Del Giovane C, Luppi F, et al. Non-steroid agents for idiopathic pulmonary fibrosis. Cochrane Database Syst Rev 2010; 9: CD003134.

38 Richeldi L, Yasothan U, Kirkpatrick P. Pirfenidone. Nat Rev Drug Discov 2011; 10: 489-490.

39 Richeldi L, Costabel U, Selman M, et al. Efficacy of a tyrosine kinase inhibitor in idiopathic pulmonary fibrosis. New Engl J Med 2011; 365: 1079-1087.

40 Seaman DM, Meyer CA, Gilman MD, et al. Diffuse cystic lung disease at high resolution CT. Am J Radiol 2011; 196: 1305-1311.

41 Borie R, Schneider S, Debray MP, et al. Severe chronic bronchiolitis as the presenting feature of primary Sjogren's syndrome. Respir Med 2011; 105: 130-136.

42 Tomassetti S, Carloni A, Chilosi M, et al. Pulmonary features of Birt Hogg Dubè syndrome: cystic lesions and pulmonary histiocytoma. Respir Med 2011; 105: 768-774.

43 Cottin V, Reix P, Khouatra C, et al. Combined pulmonary fibrosis and emphysema syndrome associated with familial SFTPC mutation. Thorax 2011; 66: 918-919.

44 Baldi BG, Santana AN, Takagaki TY, et al. Lung cyst: an unusual manifestation of Niemann Pick disease. Respirology 2009; 14 134-136.

45 Rowan C, Hansell DM, Renzoni E, et al. Diffuse cystic lung disease of unexplained cause with coexistent small airway disease: a possible causal relationship? Am J Surg Pathol 2012; 36: 228-234.

46 Yamamoto $\mathrm{T}$, Kabus $\mathrm{S}$, Klinder $\mathrm{T}$, et al. Investigation of fourdimensional computed tomography-based pulmonary ventilation imaging in patients with emphysematous lung regions. Phys Med Biol 2011; 56: 2279-2298.

47 Yamamoto T, Kabus S, von Berg J, et al. Comparison of fourdimensional (4D) CT ventilation imaging with SPECT V/Q scans. Eur Respir J 2011; 38: Suppl. 55, 256s.

48 Hubbard PL, Parker GJM, Singh D, et al. Novel ventilationperfusion ratio measurements in COPD using MRI. Eur Respir J 2011; 38: Suppl. 55, 323s.

49 Zhang W, Hubbard P, Bondesson E, et al. Ventilation-perfusion mismatch in COPD with or without emphysema: comparison of structural CT and functional OE-MRI. Eur Respir J 2011; 38: Suppl. $55,324 \mathrm{~s}$

50 Morgan AR, Parker GJ, Hubbard PL, et al. Assessment of relative regional lung compliance in patients with chronic obstructive pulmonary disease. Proc Intl Soc Mag Reson Med 2011; 19: 543.

51 Morgan AR, Parker GJ, Scott ML, et al. A novel method using proton MRI and image registration to investigate relative regional pulmonary compliance. Proc Intl Soc Mag Reson Med 2010; 18: 2520-2526.

52 Shaker SB, Dirksen A, Lo P, et al. Decline in lung density is accelerated in active smokers. Eur Respir J 2011; 38: Suppl. 55, 324s.

53 Hoesein FM, Zanen P, Ginneken BV, et al. Distribution of CTquantified emphysema: association with lung function decline. Eur Respir J 2011; 38: Suppl. 55, 843s.

54 Camiciottoli G, Bigazzi F, Diciotti S, et al. Tracheo-bronchial collapsibility in different clinically determined COPD phenotypes. Eur Respir J 2011; 38: Suppl. 55, 843s.
55 Haroon S, Jordan R, Adab P, et al. COPD case finding in primary care: a pilot study in the West Midlands, UK. Eur Respir J 2011; 38: Suppl. 55, 180 s.

56 Lyngsø AM, Gottlieb V, Backer V, et al. Early detection of COPD in primary care. The Copenhagen COPD screening project. Eur Respir J 2011; 38: Suppl. 55, 184s.

57 Price D, Halpin D, Winter R, et al. Missed opportunities to diagnose COPD. Eur Respir J 2011; 38: Suppl. 55, 82s.

58 Booth H, Georgopoulou S, Pinnock H, et al. High rates of overtreatment of COPD in primary care: what risks to patients and costs to health services? Eur Respir J 2011; 38: Suppl. 55, 181s.

59 Samaria JK, Hussain M, Yadav P, et al. Poor quality of health services at primary care level is the leading cause of uncontrolled asthma in India. Eur Respir J 2011; 38: Suppl. 55, 3763 s.

60 Termeer E, Snoeck-Stroband J, Nuiten H, et al. Exhaled nitric oxide: a useful adjunct test in assessing asthma control in primary care. A cross-sectional exploration. Eur Respir J 2011; 38: Suppl. 55, 3767s.

61 Menzies S, Wiggins J. A survey of pulse oximeter use by general practitioners in East Berkshire, UK. Eur Respir J 2011; 38: Suppl. 55, 3761s.

62 Stallberg B, Lisspers K, Montgomery S, et al. Association of comorbidity and mortality in COPD. Eur Respir J 2011; 38: Suppl. 55,2961 s.

63 Gil T, Medina C, Fernández L, et al. Do patients suffering from heart failure (HF) and chronic obstructive pulmonary disease (COPD) tolerate beta blocker (BB) treatment? Eur Respir J 2011; 38: Suppl. 55, 2962s.

64 Ghosh S, Robertson W, Smith J, et al. Short-term outcomes in community heart failure patients with chronic obstructive pulmonary disease. Eur Respir J 2011; 38: Suppl. 55, 2967s.

65 Fairbrother P, Pinnock H, Hanley J, et al. Perspectives of patients and healthcare professionals on the impact of telemedicine on hospital admissions for chronic obstructive pulmonary disease (COPD): a nested qualitative study. Eur Respir J 2011; 38: Suppl. 55, 4986s.

66 Boonsawat W. Successful implementation of asthma guidelines in Thailand: the Easy Asthma Clinic model. Eur Respir J 2011; 38 Suppl. 55, 4992s.

67 Melissant CF, Hoevenaars J. Telespirometry in the Netherlands. Eur Respir J 2011; 38: Suppl. 55, 4989s.

68 Prinsen M, Heijst van E, Schokker S, et al. The effect of integrated care on health status in COPD. Eur Respir J 2011; 38: Suppl. 55, 4993s

69 Wouters EF, Reynaert NL, Dentener MA, et al. Systemic and local inflammation in asthma and chronic obstructive pulmonary disease: is there a connection? Proc Am Thorac Soc 2009; 6: 638-647.

70 Eagan TM, Aukrust P, Ueland T, et al. Body composition and plasma levels of inflammatory biomarkers in COPD. Eur Respir J 2010; 36: 1027-1033.

71 Breyer MK, Spruit MA, Celis AP, et al. Highly elevated C-reactive protein levels in obese patients with COPD: a fat chance? Clin Nutr 2009; 28: 642-647.

72 Van den Borst B, Gosker HR, Koster A, et al. Obstructive lung disease is associated with increased abdominal visceral fat and elevated systemic adipocytokines. Eur Respir J 2011; 38: Suppl. 55, 325s.

73 Ismail I, Keating SE, Baker MK, et al. A systematic review and meta-analysis of the effect of aerobic vs. resistance exercise training on visceral fat. Obes Rev 2012; 13: 68-91.

74 Clini E, Ambrosino N. Rehabilitation in COPD patients: evergreen in pneumology and beyond. Eur Respir J 2011; 38: 514-515.

75 Vogiatzis I. Strategies of muscle training in very severe COPD patients. Eur Respir J 2011; 38: 971-975.

76 Spruit MA, Wouters EF. New modalities of pulmonary rehabilitation in patients with chronic obstructive pulmonary disease. Sports Med 2007; 37: 501-518.

77 Gloeckl R, Weber-Lange B, Halle M, et al. Effects and feasibility of different types of endurance training in patients with end stage ling disease before lung transplantation. Eur Respir J 2011; 38: Suppl. 55, 326s. 
78 Beauchamp MK, Nonoyama M, Goldstein RS, et al. Interval versus continuous training in individuals with chronic obstructive pulmonary disease-a systematic review. Thorax 2010; 65: 157-164.

79 Wijkstra PJ, Wempe JB. New tools in pulmonary rehabilitation. Eur Respir J 2011; 38: 1468-1474.

80 Sillen MJH, Sillen MJ, Speksnijder CM, et al. Effects of neuromuscular electrical stimulation of muscles of ambulation in patients with chronic heart failure or COPD: a systematic review of the English-language literature. Chest 2009; 136: 44-61.

81 Houchen L, Menon M, Harrison S, et al. Does protein supplementation enahnce the effects of resistance training in patients with COPD? Eur Respir J 2011; 38: Suppl. 55, 325s.

82 Spruit MA, Gosselink R, Troosters T, et al. Resistance versus endurance training in patients with COPD and peripheral muscle weakness. Eur Respir J 2002; 19: 1072-1078.
83 Vogiatzis I, Stratakos G, Athanasopoulos D, et al. Chest wall volume regulation during exercise in COPD patients with GOLD stages II to IV. Eur Respir J 2008; 32: 42-52.

84 Watz H, Waschki B, Meyer T, et al. Decreasing cardiac chamber sizes and associated heart dysfunction in COPD: role of hyperinflation. Chest 2010; 138: 32-38.

85 Vasilopoulu M, Vogiatzis I, Nasis I, et al. Effects of COPD severity on hemodynamic responses to exercise in patients with GOLD stages I-IV. Eur Respir J 2011; 38: Suppl. 55, 224s.

86 Janssen DJA, Spruit MA, Schols JM, et al. Stability of life-sustaining treatment preferences of patients with advanced chronic organ failure. Eur Respir J 2011; 38: Suppl. 55, 325s.

87 Janssen DJA, Spruit MA, Schols JM, et al. Predicting changes in preferences for life-sustaining treatment among patients with advanced chronic organ failure. Chest 2011; [Epub ahead of print DOI: $10.1378 /$ chest.11-1472]. 